\title{
Comparison of Sodium Thiopentone and Propofol for Electroconvusive Therapy(ECT)
}

\author{
Olajumoke T.O(FWACS/FMCA $)^{1} \quad$ Afolayan J.O(FMCA $)^{2} \quad$ EEegunrantB.A(FMCP) ${ }^{3}$ \\ RAJI S.A(MBBS) ${ }^{1}$. \\ 1.Department of Anaesthesia and Intensive Care \\ LAUTECH Teaching Hospital, Osogbo, Osun State, Nigeria \\ 2.Department of Anaesthesia and Intensive Care \\ Ekiti StateTeaching Hospital, Ado Ekiti, Ekiti State \\ 3.Department of Psychiatry, LAUTECH Teaching Hospital, Osogbo, Osun State, Nigeria
}

\begin{abstract}
Background: Seizure activity produced by Electroconvulsive Therapy(ECT) is considered as the therapeutic aspect of this form of treatment, but is accompanied by untoward physiologic consequences, mainly cardiovascular neurological in nature. The hemodynamic effects can have a significant impact in patients with underlying cardiovascular disease. A number of medications have been used during ECT including pretreatment sedation, anaesthetic agents, muscle relaxants, anticholinergics, and drugs to attenuate parasympathetic and sympathetic responses. AIMS AND OBJECTIVES: This study was carried out to compare propofol and sodium thiopentonne effectswhen used for modified electroconvulsive therapy . METHODOLOGY: After ethical approval forty patients being planned for modified electroconvulsive therapy were recruited.They were randomly allocated into sodium thiopentone and propofol groups . The two groups had propofol $2 \mathrm{mg} / \mathrm{kg}$ or sodium thiopentone $5 \mathrm{mg} / \mathrm{kg}$ respectively and then suxamethonium $1 \mathrm{mg} / \mathrm{kg}$. After fasciculation a brief pulse impulse was deliveredby psychiatrist while patient is being ventilated manually with $100 \%$ Oxygen. The duration ofseizure, the time to loss of conscioussness, incidence of complications were recorded. RESULTS: This single blinded study was carried out on 40 adult patients equally divided into two groups of 20 each to compare the haemodynamic effects and seizure activity of thiopentone sodium (GroupS) and propofol(Group P) when used as inducing agents in patients undergoing modified electroconvulsive therapy (MECT). Results showed propofol maintained significantly better haemodynamics compared to thiopentone and seizure time was significantly lower with propofol compared to thiopentone. Recovery from anaesthesia post MECT was significantly quicker with propofol compared with thiopentone. Hence,we conclude that propofol has advantage over thiopentone when used as an induction agent for modified electroconvulsive theraphy.
\end{abstract}

Keywords: Protocol, Sodium thiopentone, Electroconvulsive therapy.

DOI: $10.7176 / \mathrm{JBAH} / 11-16-02$

Publication date:August $31^{\text {st }} 2021$

\section{INTRODUCTION}

Electroconvulsive therapy(ECT) employs generalized seizures induced electrically to treat symptoms of psychiatry disorders which includes schizophrenia, mania, depressive illness e.t.c.It is often used as second line management option after pharmacological treatment . Seizure activity produced by ECT is considered as the therapeutic aspect of this form of treatment, but is accompanied by untoward physiologic consequences(3). The hemodynamic effects could have a significant impact in patients with underlying cardiovascular disease. During the few seconds following ECT stimulus there may be temporary drop in blood pressure, this may be followed by a marked increase in heart rate which may then lead to a rise in blood pressure.Upon awakening, a patient may experience a brief period of confusion, headache or muscle stiffness. Since no surgical procedure accompanies ECT, any morbidity or mortality is especially unfortunate, and may be consequent only to treatment or to the anaesthetic.

\section{METHODOLOGY}

After approval from the hospital ethical committee, forty patients of ASA 1 and II between ages of 18 and 60 being planned for Modified Electroconvulsive Therapy(MECT) were recruited sequentially after obtaining conscent from them .All patients with history of hypertension or any cardiorespiratory dissorders, epilepsy or allergic reactions to any of the drugs to be used in the study were excluded.

All patients were randomly divided into two groups by computer generated table of random numbers in a double blinded fashion according to the induction agent to be given.

All patients were reviewed a day before and were fasted eight hours before the procedure but were allowed to continue their antipsychotic medications.

On the morning of the procedure intravenous lines were secured, monittors were attarched for baseline blood pressure, pulse rate, oxygen saturation and psychiatrist were allowed to attarch their ECT electrodes. 
Patients were then premeditated with $0.5 \mathrm{mg}$ atropine, preoxygenated for 3 minutes, general anaesthesia induced with intravenous anaesthetic agent as allocated.At the loss of eyelash reflex intravenous suxamethonium was given for neuromuscular paralysis. Size 4 Guedel airway was inserted after fasciculation has subscided to prevent tongue from falling on the airway and a brief pulse stimulus(90 -120volts MECT) was given by psychiatrist for 2 msecs. Thereafter patients were subsequently ventilated with $100 \%$ oxygen from a Bain circuit connected to anaesthetic machine at a rate of 12 breaths per minutes until return of spontaneous respiration.All patients were monittored for changes in the blood pressure, pulse rate, respiratory rate, oxygen saturation every 5 minutes. The time from administration of induction agent to loss of eye lash reflex , the quality of relaxation,the duration of seizure, recovery time and complication were all taken.All data gotten were analysed by SPSS(version 16)

RESULTS

\begin{tabular}{llll}
\hline PARAMETER & GROUP P & GROUP S & P value \\
\hline AGE & $54+\_5.6$ & $50+\_5.2$ & 0.54 \\
\hline
\end{tabular}

Both groups were comparable in terms of age

TABLE 2: Baseline vital signs

\begin{tabular}{|c|c|c|c|}
\hline PARAMETERS & GROUP P & GROUP S & P value \\
\hline Pulse Rate & $91.2(31.9)$ & $87.9(12.3)$ & 0.55 \\
\hline DBP & $87.4(12.4)$ & $85.6(14.3)$ & 0.46 \\
\hline SBP & $136.2(19.0)$ & $131.2(12.0)$ & 0.45 \\
\hline SPO2 & 98 & 99 & 0.54 \\
\hline $\mathbf{R R}$ & 18 & 20 & 042 \\
\hline
\end{tabular}

Basline vitals signs were not significantly different in both groups

TABLE 3: Time to loss of eyelash reflex

\begin{tabular}{l|lll}
\hline & Group P & Group S & P value \\
\hline Time to loss of reflex & 1 & 2 & 0.02 \\
\hline
\end{tabular}

The average time to loss of eye lash reflex was shorter in the sodium thiopentone and this was significant.

Table 4:Duration of seizure

\begin{tabular}{llll}
\hline & Group P & Group S & P value \\
\hline Duration of seizure+_S & $30+\_11.0$ & $40.5+\_16.5$ & 0.001 \\
\hline
\end{tabular}

Duration of seizure was significantly different between the two.

Table 5: Recovery time

\begin{tabular}{l|lcl} 
& Group P & Group S & P value \\
\hline Recovery time & 7.8 & 10.2 & 0.002 \\
\hline
\end{tabular}

The recovery time was shorter in the propofol group.

Table 6: Change in vital signs

\begin{tabular}{llllll}
\hline & $\mathrm{SDP}(\mathrm{mmHg})$ & $\mathrm{DBP}(\mathrm{mmHg})$ & $\mathrm{PR}(\mathrm{b} / \mathrm{m})$ & $\mathrm{RR}(\mathrm{Cycle} / \mathrm{min})$ & $\mathrm{SP02}(\%)$ \\
Group P & 10 & 8 & 16 & 4 & $\mathrm{I}$ \\
Group S & 22 & 14 & 24 & 6 & 2 \\
P value & 0.02 & 0.03 & 0.002 & 0.06 & 0.5 \\
\hline
\end{tabular}

The changes in vital signs were significant in the systolic, diastolic blood pressures, pulse rate and the difference was higher in the thiopentone group.

\section{Discussion}

The practise of ECT was introduced by Cerletti and Bini in tge year 1938 and it was a modality of treatment for a large variety of psychiatry illness which acute depression, schizophrenia, acute mania, psychosis most especially when there is pharmacotherapy failure2.Early in those days direct ECT was given directly to patients without anaesthesia with high incidence of complications like fractures, joint dislocations, and muscle tears recorded then3.The introduction of short acting anaesthetic agents like propofol, sodium thiopentone, suxamethonium in a technique known as modified electroconvulsive therapy make the procedure more simple and devoid of complications

This study aim at comparing propofol and thiopentone for modified electroconvulsive therapy

In this study, the mean of seizure duration in the sodium thiopental group was longer than that in the propofol group $(40.5 \pm 16.5 \mathrm{sec}$ versus $30 \pm 11.0 \mathrm{sec})$, which was statistically significant $(\mathrm{P}=0.001)$.

Bauer4 et al in their studyobtained simikar result and also consistent with other studies 5, 6. However, it was in contrast with the findings of a study by kumar et al 7 , where they concluded that the mean of seizure 
duration in the propofol group was significantly $(\mathrm{P}<0.01)$ longer than that in the sodium thiopental group.

In this study, the mean of baseline and pre-ECT SBP and DBP were similar in the both groups however the systolic and diastolic pressures were higher in the thiopentone group than propofol group at 5mins post ECT however it was not significant.The difference in the post ECT pulse rate, SBPand DBP were significant while SP02 and respiratory rate were not significant.

These findings are consistent with findings of other researchers 6,8 , which also showed that the mean of arterial blood pressure in the propofol group was lower as compared to the sodium thiopental group.

Generally, the data collected in this study indicated no significant difference of baseline and pre-ECT hemodynamic parameters between the Propofol and sodium thiopental groups. Although there was an increase in these parameters of both groups immediately after seizure, but the increase in the heart rate, SBP, DBP were less in propofol group compared to sodium thiopental group. This implies that the hemodynamic conditions in the propofol group varied insignificantly before and after the ECT, which is consistent with the findings of Omprakash et al 6and Zaidi and Khan (2000) 8who believed that Propofol provides a stable hemodynamic condition during ECT. Another interpretation to justify such findings is that, the common hemodynamic changes after ECT include bradycardia immediately followed by tachycardia and eventually hypertension and since Propofol was found in other studies to have caused more hypotension as compared to sodium thiopental, so it can effectively prevent the subsequent ECT-induced hypertension 9, 10. Even some studies have demonstrated that induction of anesthesia with propofol can further prevent hemodynamic responses of laryngoscopy and tracheal intubation 11 .

\section{Conclusion}

Based on this study propofol is recommended for induction for ECT based on the better haemodynamic stability and rapid recovery pattern observed.Propofol is also beneficial for induction of anesthesia during ECT in patients with hypertension, hyperthyroidism, ischemic heart disease and other medical conditions in which the a drastic increase in hemodynamic parameters may be harmful to patients. Though seizure time is shorter in propofol it is still enough to achieve effect with the ECT.

\section{LIMITATION}

The patients were only assessed only at 5 minutes post ECT, possibly if they were assessed regularly more than once postoperatively the pattern of result might be different.

The sample size used was forty, possibly if a larger sample size was used the result may be different.

\section{RECOMMENDATION}

It is recommended that future researches can be done using a larger sample size and patients should be assessed regularly at least for an hour post ECT.

\section{REFRENCES}

1 Cerletti U, Bini L.Electroshock article.Acad Med.19389; 64:136.

2 Kalinowsky LB.History of conclusive therapy.Ann NY Academy Sci.1986462;1-4.

3 Elkinci M, Hsu JJ, Brick M, Brain RA.Diazepam as anticonvulsant agent in ECT. AMJ Psychiatr.1994; 120:6.

4 Bauer, J., Hageman, I., Dam, H., Báez, A., Bolwig, T., Roed, J., ... Jegersen, M. B. (2009). Comparison of Propofol and Sodium Thiopental as Anesthetic agents for Electroconvulsive therapy: A Randomized, Blinded Comparison of Seizure Duration, Stimulus Charge, Clinical effect, and Cognitive side effects. The Journal of ECT, 25(2), 85-90. http://dx.doi.org/10.1097/YCT.0b013e31818a0203hi

5 Ingram, A., Schweitzer, I., Ng, C. H., Saling, M. M., \& Savage, G. (2007). A Comparison of Propofol and Thiopentone use in Electroconvulsive therapy: Cognitive and Efficacy effects. The Journal of ECT, 23(3), 158-62. http://dx.doi.org/10.1097/yct.0b013e318070d1e9

6 Zaidi, N. A., \& Khan, F. A. (2000). Comparison of Thiopentone Sodium and Propofal for Electro-Convulsive Therapy (ECT). Journal-Pakistan Medical Association, 50(2), 60-2. PMIDPubmed: 10769525.

7 Kumar, A., Sharma, D. K., \& Mani, R. (2012) A Comparison of Propofol and Thiopentone for Electroconvulsive Therapy. Journal of Anaesthesiology, Clinical Pharmacology, 28(3), 353-7. http://dx.doi.org/10.4103/ 0970-9185.98337

8 Omprakash, T., Ali, M. I., Anand, B., Devi, M. G., \& Surender, P. (2008). Comparision of Thiopentone Sodium and Propofol in ECT anaesthesia. Indian Journal of Psychological Medicine, 30(1), 48-51. http://dx.doi.org/ 10.4103/0253-7176.43134

9 Miller, R. D., \& Pardo, M. (2011). Basics of Anesthesia (6th ed., pp. 125-134). Philadelphia, PA. Expert Consult: Elsevier Health Sciences.

10 Sadock, B. J. (2010). Kaplan and Sadock's Synopsis of Psychiatry (10th ed., pp. 357-365). Philadelphia, PA: Wolters Kluwer Health. 
Jarineshin, H., \& Razmpour, M. (2006). Comparison of Hemodynamic changes of Propofol and Sodium

11 Thiopental during Induction of Anesthesia and Tracheal intubation. Hormozgan Medical Journal, 10(3), 21521. Retrieved from http://hmj.hums.ac.ir/browse.php?a_code=A-10-2-227\&slc_lang=en\&sid=1 